\title{
Programmable data acquisition system for research measurements from meteorological radiosondes
}

Article

Accepted Version

Harrison, G., Nicoll, K. and Lomas, A. (2012) Programmable data acquisition system for research measurements from meteorological radiosondes. Review of Scientific Instruments, 83 (3). 036106. ISSN 0034-6748 doi:

https://doi.org/10.1063/1.3697717 Available at https://centaur.reading.ac.uk/32240/

It is advisable to refer to the publisher's version if you intend to cite from the work. See Guidance on citing.

Published version at: http://rsi.aip.org.idpproxy.reading.ac.uk/resource/1/rsinak/v83/i3/p036106_s1

To link to this article DOI: http://dx.doi.org/10.1063/1.3697717

Publisher: AIP

Publisher statement: Copyright 2012 American Institute of Physics. This article may be downloaded for personal use only. Any other use requires prior permission of the author and the American Institute of Physics.

All outputs in CentAUR are protected by Intellectual Property Rights law, including copyright law. Copyright and IPR is retained by the creators or other copyright holders. Terms and conditions for use of this material are defined in the End User Agreement. 


\section{CentAUR}

Central Archive at the University of Reading

Reading's research outputs online 


\title{
Accepted by Reviews of Scientific Instruments
}

http://dx.doi.org/10.1063/1.3697717

\section{Programmable data acquisition system for research measurements from meteorological radiosondes}

\author{
R. G. Harrison, K.A. Nicoll and A.G. Lomas \\ Department of Meteorology, University of Reading, Reading RG6 6BB, U.K.
}

\begin{abstract}
A programmable data acquisition system to allow novel use of meteorological radiosondes for atmospheric science measurements is described. In its basic form it supports four analogue inputs at 16 bit resolution, and up to two further inputs at lower resolution configurable instead for digital instruments. It also provides multiple instrument power supplies $(+8 \mathrm{~V},+16 \mathrm{~V},+5 \mathrm{~V}$ and $-8 \mathrm{~V})$ from the $9 \mathrm{~V}$ radiosonde battery. During a balloon flight encountering air temperatures from $+17^{\circ} \mathrm{C}$ to $-66^{\circ} \mathrm{C}$, the worst case voltage drift in the $5 \mathrm{~V}$ unipolar digitisation circuitry was $20 \mathrm{mV}$. The system liberates a new range of low cost atmospheric research measurements, by utilising radiosondes routinely launched internationally for weather forecasting purposes. No additional receiving equipment is required. Comparisons between the specially instrumented and standard meteorological radiosondes show negligible effect of the additional instrumentation on the standard meteorological data.
\end{abstract}

Keywords: radiosonde, meteorological instruments, data acquisition, microcontroller, temperature sensitivity 
A novel use of a meteorological radiosonde as an inexpensive measurement platform for atmospheric research is made possible when a data acquisition system ${ }^{1}$ and further instrumentation is added. Because radiosondes are launched at many sites around the world daily or more frequently to meet operational meteorological needs, flight (and therefore measurement) opportunities are in principle abundant. To support a range of disparate digital and analogue instruments, a programmable data acquisition system is required, to process and format the samples obtained. The data acquisition system established for an analogue (Vaisala RS80) radiosonde $^{2}$ has now been updated for a digital (Vaisala RS92) radiosonde, widely used by European meteorological services. A significant improvement is the implementation of high resolution (16bit) and low resolution (10bit) analogue data channels, and the provision of multiple $(+8 \mathrm{~V},+16 \mathrm{~V},+5 \mathrm{~V}-8 \mathrm{~V})$ supplies to power digital and analogue circuitry attached. Importantly, no additional receiving hardware beyond the standard configuration used by meteorological services is needed. This data system - "PANDORA" (Programmable ANalogue and Digital Operational Radiosonde Accessory) - fits in a small box (dimensions $12 \times 6.5 \times 4.5 \mathrm{~cm}$, mass $110 \mathrm{~g}$ ) strapped to the radiosonde by nylon wire ties. The approach has already been successfully used to facilitate opportunist cloud charge ${ }^{3}$, Saharan dust $^{4}$ and volcanic ash ${ }^{5}$ measurements aloft.

The Vaisala RS92 radiosonde and its Digicora receiving system conventionally transfer the standard in situ meteorological measurements of pressure (P), temperature $(T)$, and relative humidity $(U)$, together with a report of GPS location over a UHF $(403 \mathrm{MHz})$ radio link. In a feature originally intended to allow the use of ozone sensors, the radiosonde's internal data system can accept a further 64 bits of serial data in every measurement cycle, repeating about once per second. The PANDORA system interleaves its science data within this serial data window. The extra science data (transferred as four word variables) is written to an additional file by the standard Digicora system used to receive the radiosonde data at the surface. By time-aligning this file with the standard meteorological data file, the related meteorological measurements and position can be retrieved.

Figure 1 provides an overview schematic of the add-on measurement system for the radiosonde. It interfaces the sensor data to the serial data bus of the radiosonde, and generates the power supplies from the radiosonde's alkaline battery. A Peripheral Interface Controller (PIC) microcontroller running at $4 \mathrm{MHz}$ is used to control the analogue to digital convertors and the serial data exchange. Serial data buses are used by the microcontroller to request and obtain data from two 16 bit analogue to digital convertors, (A2D1 and A2D2), each of which have two unipolar (5V range) analogue inputs (channels $\mathrm{ChO}$ to $\mathrm{Ch} 3$ ). Three further inputs are available, directly to the microcontroller. These are software configurable, programmed to provide two low resolution (10bit) input channels (Ch4 and $\mathrm{Ch} 5$ ) and a serial data line. The input data obtained is loaded into a First-InFirst-Out (FIFO) shift register on each measurement cycle, ready for rapid ( $\sim 500 \mathrm{kHz}$ clock) transfer when the radiosonde makes a data request. The system consumes $\sim 3 \mathrm{~mA}$ from the radiosonde's $9 \mathrm{~V}$ battery.

The multiple inputs of the system are under the software control of the PIC program. As described, in its basic mode, this program transfers 64 bits of data every second, which corresponds to four word values from each of the 16-bit data channels. For an ascent rate of $5 \mathrm{~ms}^{-1}$, this amounts to one set of samples for $5 \mathrm{~m}$ of vertical displacement. If additional measurements are needed from other sensors, these must be interleaved in these transmissions and perhaps reported less frequently, or combined with elementary data compression. Some elementary processing is possible, such as 
averaging, or repeated sampling to increase the effective analogue to digital conversion resolution. However, because only integer arithmetic is available, computing the variability, as needed to derive air turbulence from magnetometer samples ${ }^{6}$, provides a complication. Rather than sending a long burst of stored samples for the later calculation of standard deviation, storing several (averaged) measurements in the PIC and re-ordering them with the in-place sort algorithm of straight insertion ${ }^{8}$, instead allows the efficient transmission of just the single value of the measurements' inter-quartile range.

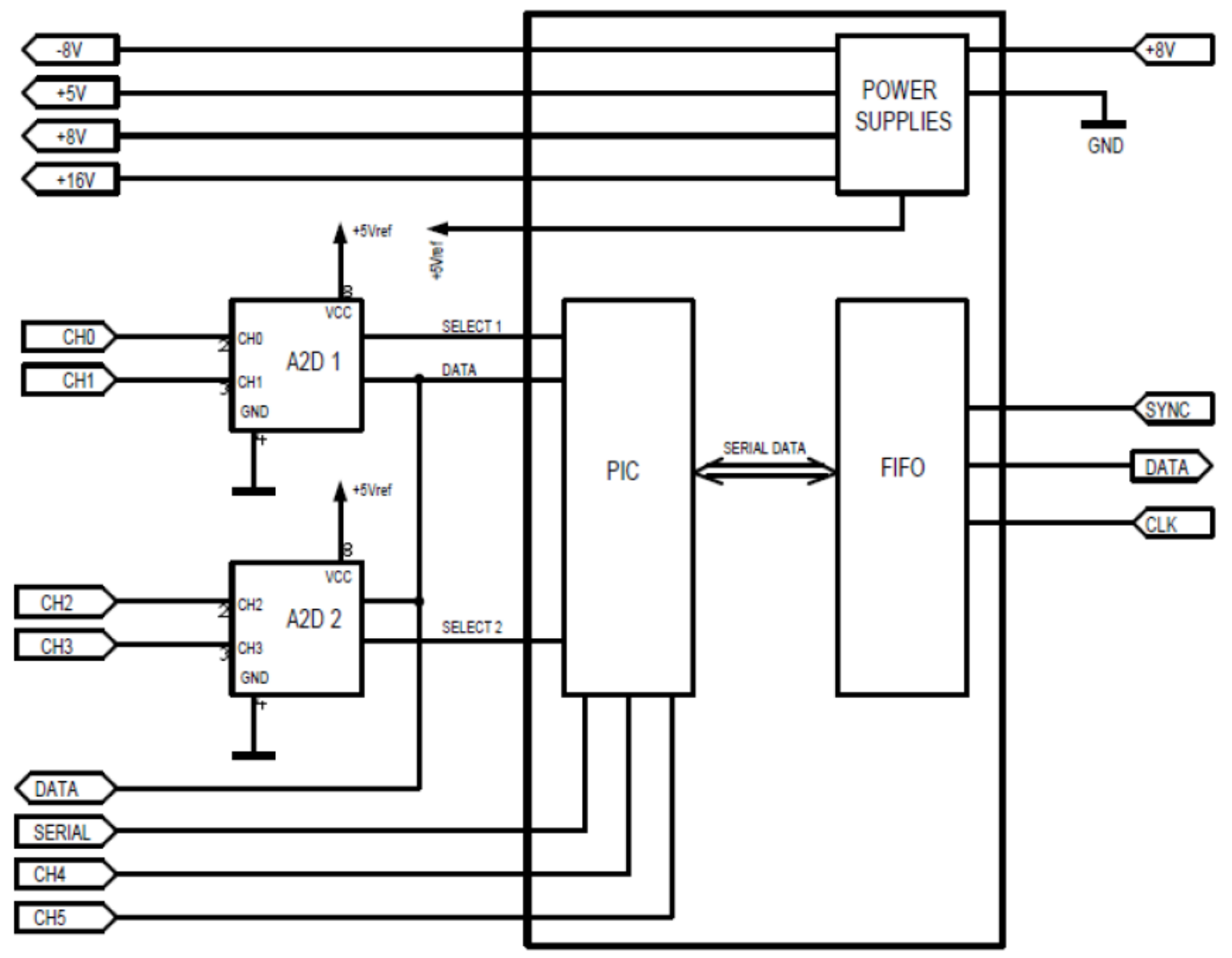

Figure 1. Block diagram of the Programmable ANalogue and Digital Operational Radiosonde Accessory (PANDORA), managed by a programmed Peripheral Interface Controller (PIC, type 16F676). Data requests made by the radiosonde on the SYNC line cause the most recent measurement cycle of data loaded into the First-In-First-Out (FIFO) shift register (type 7403) to be clocked serially to the radiosonde using the DATA and CLK lines. In each measurement cycle the PIC requests input voltage on channels $\mathrm{CHO}, \mathrm{CH} 1, \mathrm{CH} 2$ and $\mathrm{CH} 3$ via two dual channel 16bit analogue to digital convertors (type LTC1875), and also makes low resolution (10bit) voltage conversions on channels $\mathrm{CH} 4$ and $\mathrm{CH} 5$. Using a flying capacitor voltage convertor (type 7660), the $+8 \mathrm{~V}$ radiosonde supply is inverted to $-8 \mathrm{~V}$ and doubled to $+16 \mathrm{~V}$. Two independent $+5 \mathrm{~V}$ supplies are also generated (using LP2950 regulators), one used internally as a voltage reference for the analogue to digital convertors, and one available to supply additional instrumentation connected. 
Tests have been made on the system which, during an atmospheric flight, may encounter temperatures from $+30^{\circ} \mathrm{C}$ to $-65^{\circ} \mathrm{C}$ and pressures from $1040 \mathrm{hPa}$ to $25 \mathrm{hPa}$. Firstly, the battery voltage was monitored during a flight which shows a steady decrease from $+8.3 \mathrm{~V}$, to an end point of about 7.3V (Figure 2a). Secondly, the stability of the analogue to digital convertors was assessed, using a temperature stable voltage reference (type LT1027, generating $5.00 \mathrm{~V} \pm 2 \mathrm{ppm} /{ }^{\circ} \mathrm{C}$ ), monitored through a $10 \mathrm{k} \Omega$ : $10 \mathrm{k} \Omega$ potential divider formed from $\pm 15 \mathrm{ppm} /{ }^{\circ} \mathrm{C} 0.1 \%$ metal film precision resistors. The thermal drift of the analogue to digital convertors primarily arises from variations in the $5 \mathrm{~V}$ internal voltage reference (type LP2950, temperature coefficient $\pm 50 \mathrm{ppm} /{ }^{\circ} \mathrm{C}$ ). From these measurements, an absolute error of $20 \mathrm{mV}$ for the analogue to digital convertors was determined during a flight with air temperatures from +17 to $-66^{\circ} \mathrm{C}$. Finally, a bead thermistor was deployed on a further flight, wired in a potential divider configuration excited by the $+5 \mathrm{~V}$ supply, to monitor the air temperature. Although the radiosonde itself carries an air temperature sensor, the thermistor was added to test the data processing, and, in particular, establish that the merging of the radiosonde meteorological data with the PANDORA was carried out correctly. The negligible vertical offset between the radiosonde air temperature and the thermistor-derived air temperature, especially at $0.5 \mathrm{~km}$ aloft (Figure $2 \mathrm{~b}$ ), demonstrates that there are no artefacts of the data processing which could cause the PANDORA measurements to be attributed to an incorrect vertical position.

(a)

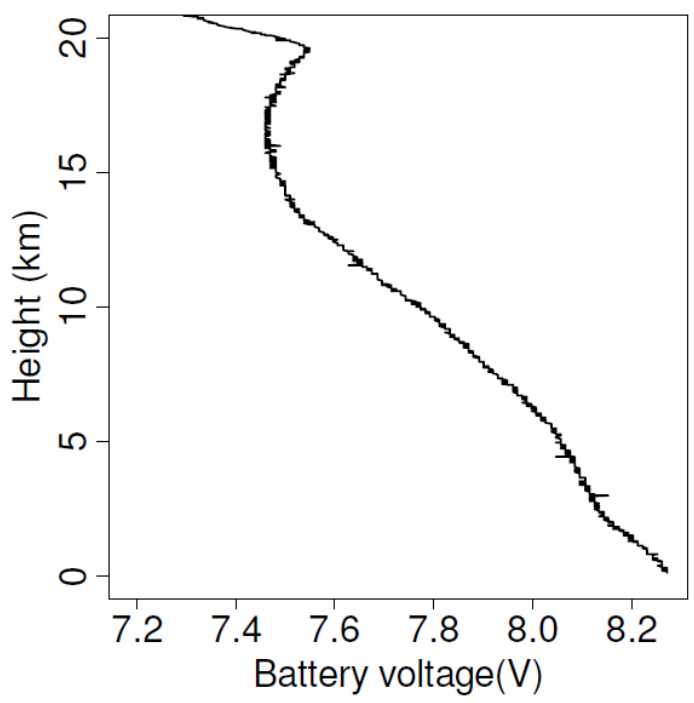

(b)

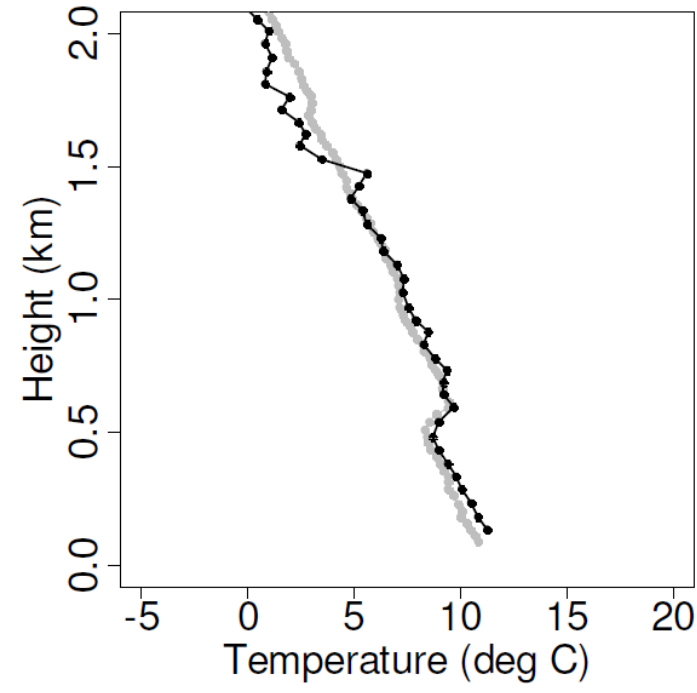

Figure 2. Results of flight tests performed on the PANDORA system during the ascent stage of a radiosonde flight to $20 \mathrm{~km}$. (a) Radiosonde battery voltage (nominally 6 alkaline AA cells of 1.5V), (b) temperature profile measured by the radiosonde (grey) and by a thermistor attached to the PANDORA box (black).

A further consideration for operational radiosondes is that the standard meteorological measurements for which the radiosondes are funded and flown must not be affected by the additional instrumentation. Although the PANDORA box is strapped to the opposite side of the radiosonde from the meteorological sensors, it is conceivable that small changes in airflow might arise, which could lead to a small measurement bias. This possibility was assessed by flying two radiosondes beneath the same helium balloon, only one of which carried a PANDORA. The comparison between the $\mathrm{P}, \mathrm{T}$ and $\mathrm{U}$ measurements made by the two systems is shown in Figure 3 , 
which shows the standard deviation of the differences between the two systems for four different flights (flights 2 to 5 ), and one control flight whereby two standard RS92 sondes were flown together (flight 1). The standard deviations of the differences are compared with the "reproducibility in soundings" specifications of the radiosonde manufacturer ${ }^{9}$ (dashed lines in Figure 3), which represent the standard deviations between twin RS92 soundings up to about $15 \mathrm{~km}$. From Figure 3, all of the PTU measurements lie within the reproducibility specifications, suggesting a negligible effect of the additional PANDORA instrumentation on the standard meteorological measurements.

(a)

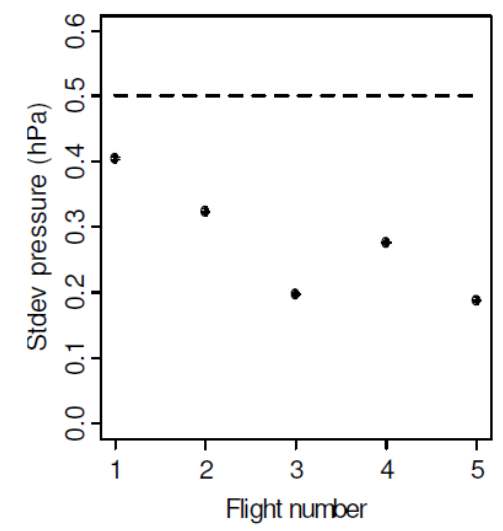

(b)

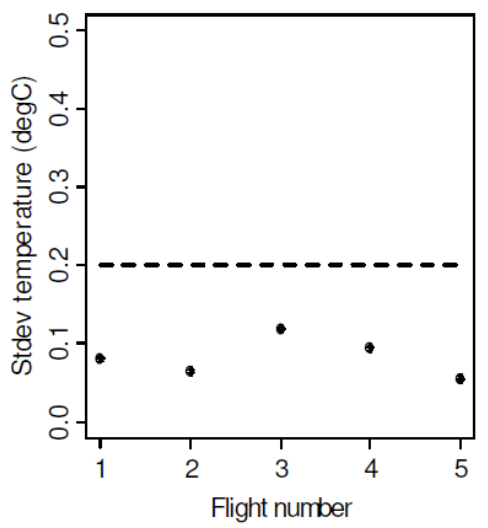

(c)

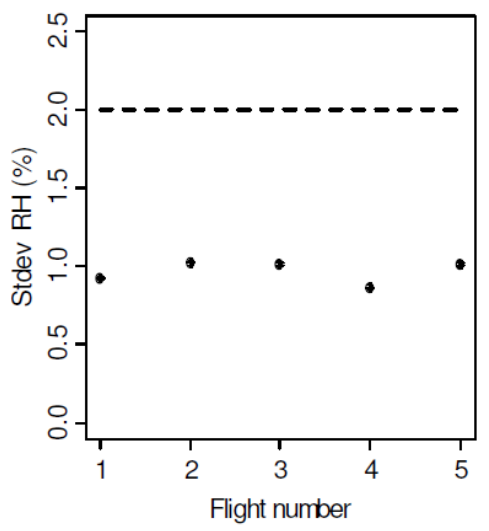

Figure 3. Comparison of specially instrumented PANDORA sonde with a standard operational RS92 radiosonde, both flown beneath the same balloon (flights 2 to 5). Flight 1 denotes a control flight in which two standard RS92s were flown together to give an idea of the repeatability of sonde measurements. Plots show the standard deviation of all the samples of the differences between (a) pressure, (b) temperature and (c) relative humidity $(\mathrm{RH})$ as measured by the two sondes, between the surface and $\sim 15 \mathrm{~km}$ altitude (pressure levels from $1000 \mathrm{hPa}$ to $100 \mathrm{hPa}$ ). (The standard deviations are computed from 1570, 1531, 1715, 1526, and 1530 data points for flights 1 to 5 respectively. Dashed lines denote the standard deviation of differences in twin soundings of the RS92 between pressure levels of 1000 to $100 \mathrm{hPa}$, as specified by the radiosonde manufacturer.)

Although used here with a Vaisala RS92 radiosonde, the same basic hardware can, with suitable programming, be adapted for use with other radiosonde systems able to retransmit serial data. In summary, the PANDORA system provides a new science capability for the operational radiosonde used by weather services, without adversely affecting the performance of the standard meteorological sensors.

\section{Acknowledgements}

This work was supported by the UK's Natural Environment Research Council, grant reference NE/H002081/1 (More Operational Radiosonde SEnsors, MORSE). G. Rogers and R.Wilson helped with the electronics development, and the UK Met Office upper air team facilitated the radiosonde comparisons. 


\section{References}

${ }^{1}$ K.A. Nicoll and R.G. Harrison, Met. Tech. Int. Nov 2010, 140 (2010).

${ }^{2}$ R.G. Harrison, Rev. Sci. Instrum. 76, 026103 (2005).

${ }^{3}$ K.A. Nicoll and R.G. Harrison, Rev. Sci. Instrum. 80, 014501-4 (2009).

${ }^{4}$ K.A. Nicoll, R.G. Harrison and Z. Ulanowski, Environ. Res. Lett., 6, 014001(2011).

${ }^{5}$ R.G. Harrison, K.A. Nicoll, Z. Ulanowski, T.A. Mather, Environ. Res. Lett., 5, 024004, (2010).

${ }^{6}$ R.G. Harrison, G.W. Rogers, and R.J. Hogan, Rev. Sci. Instrum. 78, 12, 124501 (2007).

${ }^{7}$ R. G. Harrison, A.M. Heath, R. J. Hogan and G. W. Rogers, Rev. Sci. Instrum. 80, 026108 (2009).

${ }^{8}$ W.G. Press , B. P. Flannery, S.A. Teukolsky and W. T. Vetterling Numerical Recipes in Pascal: The Art of Scientific Computing ( $1^{\text {st }}$ edition, Cambridge University Press, 1990)

${ }^{9}$ Vaisala RS92 datasheet:

http://www.vaisala.com/Vaisala\%20Documents/Brochures\%20and\%20Datasheets/RS92-D-

Datasheet-B210763EN-B-LoRes.pdf 